\title{
Experimental Study on the Flow Behavior of Grout Used in Horizontal Directional Drilling Borehole Grouting to Seal Mining- Induced Overburden Fractures
}

\author{
Jinfeng Ju, ${ }^{1,2}$ Jialin Xu $\mathbb{D}^{3,4}$ and Jing Yang ${ }^{5}$ \\ ${ }^{1}$ The National and Local Joint Engineering Laboratory of Internet Application Technology on Mine, China University of Mining \\ and Technology, Xuzhou, Jiangsu 221008, China \\ ${ }^{2}$ IoT/Perception Mine Research Center, China University of Mining and Technology, Xuzhou, Jiangsu 221008, China \\ ${ }^{3}$ State Key Laboratory of Coal Resources and Safe Mining, Xuzhou, Jiangsu 221116, China \\ ${ }^{4}$ School of Mines, China University of Mining and Technology, Xuzhou, Jiangsu 221116, China \\ ${ }^{5}$ Shendong Coal Group Co., Ltd., China Energy, Yulin, Shaanxi 719315, China \\ Correspondence should be addressed to Jialin Xu; xujlcumt@163.com
}

Received 21 July 2020; Revised 12 August 2020; Accepted 29 December 2020; Published 12 January 2021

Academic Editor: Eliahu Rosenthal

Copyright (C) 2021 Jinfeng Ju et al. This is an open access article distributed under the Creative Commons Attribution License, which permits unrestricted use, distribution, and reproduction in any medium, provided the original work is properly cited.

\begin{abstract}
The development of water-conducting fractures from underground coal mining is a geological cause of groundwater loss. Sealing mining-induced rock fracture channels through borehole grouting is an effective way to protect groundwater resources. A groundbased engineering test was conducted at the Gaojiabao coal mine that utilized horizontal directional drilling (HDD) to grout and seal water-conducting overburden fractures. This study carried out a theoretical and experimental exploration using HDD to evaluate the development characteristics and grout hydraulic conductivity of these mining-induced fractures. The results showed that, as a result of varying fracture morphologies in different zones of the mining overburden, multiple fracture types were sequentially exposed as the HDD borehole advanced from the original rock mass outside the mining area towards the mininginduced fractured rock mass. The fracture types were exposed in the following order: compressive shear fractures, tensile failure fractures, and bed separation fractures. Moreover, the void characteristics of the exposed fractures in the borehole were significantly different at different drilling horizons, which affected the flow behavior and sealing performance of the injected grout. Lastly, three typical orders in which the different types of fractures were sequentially exposed by the borehole were summarized, and further analysis of the orders led to a scheme for determining drilling horizons favorable for efficient fracture sealing. The results of this study will enable efficient grout sealing of the fractures caused by mining and reduce groundwater loss.
\end{abstract}

\section{Introduction}

Underground coal mining produces movement and destruction of the overburden in the form of mining-induced fractures. Mining-induced fractures not only provide a pathway for groundwater loss but also constitute a geological source of the degradation of ground-surface ecosystems [1, $2]$. Therefore, reasonable control of the water seepage capacity of fracture channels is crucial to the protection of groundwater in coal mining areas [3,4]. Grout sealing is a well-developed water control method currently used in subsurface engineering applications [5-7]. Grout sealing works by constructing grout holes in a fractured rock mass and injecting those holes with sealing materials, such as cement and clay, such that the fracture voids are effectively filled, and channel isolation and water blocking are achieved.

The Gaojiabao coal mine is located in the Binchang mining area in Shaanxi, China. As the mine's coal seam roof contains a very thick, water-rich aquifer (i.e., the Luohe aquifer), it has been subject to the risk of an influx of water from the roof for a long time. To reduce the underground drainage burden and maximize the conservation of groundwater resources, an engineering test was carried out to evaluate the practicability of using HDD to seal mining-induced 
water-conducting fractures in the overburden [8]. It has been observed in practice that, although various sealing materials such as fly ash, cement, water glass, clay, walnut shells, and cottonseed hulls have been implemented on site, none have exhibited satisfactory water blocking performance. Owing to the diverse development patterns of mining-induced water-conducting fractures, strong fracture conductivity, and the varying flow behavior of grout in different fractures, one or more of the following phenomena was often observed to take place during grouting: (1) fractures could not be effectively sealed (i.e., the grouting materials leaked into the underground goaf), (2) grouting materials clogged the boreholes earlier than expected, and (3) additional water leakage was observed when drilling continued after successful sealing. Each of these phenomena greatly compromised the sealing performance of the mining-induced fracture channels. It was obvious that these phenomena were closely related to the development characteristics (e.g., fracture aperture) and grout hydraulic conductivity of the borehole-exposed water-conducting fractures. Accurate determination of a reasonable drilling trajectory based on the flow behavior of sealing grout in water-conducting fractures is the key to ensuring effective fracture sealing.

In coal mining, the theory and practice of grout sealing has focused on reinforcing the surrounding rock mass, water blocking in shaft and roadway construction [7, 9-14], and preventing water inrush when mining below a confined aquifer [15-17]. Relevant research has centered on the selection of water blocking materials, law of grout diffusion, optimization of the grouting procedure, and evaluation of the fracture sealing performance, which has laid an important foundation for the practice of grout sealing in mining-induced overburden fractures. However, the fractures to be sealed in the rocks surrounding roadways or coal seam floor rocks are significantly different from the mining-induced overburden fractures in terms of their development morphologies, as well as their abilities to conduct and confine grout (Figure 1). Therefore, it is difficult to directly apply the existing research results for the former fracture types to engineering practice with the latter types, leading to the aforementioned dilemma in the grout sealing of water-conducting fractures in the coal seam roof of the Gaojiabao coal mine. The fractures in the rocks surrounding the roadway or in coal seam floor rocks are mostly compressive shear fractures generated by the concentrated stress that results from mining disturbances or preexisting fractures generated by the diagenetic process. These fractures are distributed in a relatively enclosed space and sufficiently confine the grout (except for the fractures at the grouting end, fractures in a rock mass are not connected to other free spaces), thereby enabling good sealing performance. In contrast, mining-induced overburden fractures tend to be tensile fractures generated during the breaking and rotation of strata, and the channel sizes of these fractures are obviously larger than the previously mentioned fractures [18]. As mining-induced overburden fractures have good connectivity to the underground mining space, the grout often gushes into the goaf under the action of gravity in a phenomenon known as grout escape. This results in significantly higher difficulty in grout sealing these fractures.
Therefore, the development of a grouting procedure or method favorable for efficient fracture sealing based on full consideration of the special development morphology and grout hydraulic conductivity of mining-induced overburden fractures is essential. Accordingly, this study carried out a theoretical and experimental exploration using HDD to evaluate the development morphology and grout hydraulic conductivity of fractures in light of the engineering test performed in the Gaojiabao coal mine, which utilized HDD borehole grouting to seal water-conducting overburden fractures and aimed to provide a basis and support for improving the sealing efficacy of mining-induced overburden fractures.

\section{Case Study}

2.1. Engineering Background. The Gaojiabao coal mine is located in Xianyang City, Shaanxi Province. The mine field is approximately $25.7 \mathrm{~km}$ long in the east-west direction, $16.6 \mathrm{~km}$ wide in the north-south direction, and has an area of approximately $219.1681 \mathrm{~km}^{2}$. The designed production capacity of the mine is 5 million $\mathrm{t} / \mathrm{a}$, and it has a service life of 62.5 years. The No. 4 coal seam is currently the primary working coal seam of the mine. It has an average thickness of $9.8 \mathrm{~m}$ and is subjected to fully mechanized top coal cave mining. Owing to the special hydrogeological conditions in this region, an exceedingly thick, water-rich aquifer (i.e., the Luohe aquifer) stretches across much of the coal measure strata. The aquifer is $400-440 \mathrm{~m}$ thick and has a permeability coefficient of $0.05471-1.08265 \mathrm{~m} / \mathrm{d}$. The aquifer is located $30-$ $110 \mathrm{~m}$ above the No. 4 coal seam and poses a serious water hazard to the on-going coal extraction at the underground working face. The mining-induced water-conducting fractures in the overburden directly connect to the aquifer, which has resulted in a large amount of water gushing into the underground goaf. In the No. 1 panel, for example, longwall faces 101, 102, and 103 still face a continuous increase in water inflow under limited-height mining (i.e., within a mining height of $5 \mathrm{~m}$ ), and the maximum water inflow on one side has reached $720 \mathrm{~m}^{3} / \mathrm{h}$, with a total of water inflow of $800 \mathrm{~m}^{3} / \mathrm{h}$ even after mining of the three faces was complete. This poses a significant threat to safe and efficient mine production and mine drainage. To reduce the underground drainage burden, reduce the roof water hazard, and protect groundwater resources as much as possible, a ground-based engineering test was carried out that evaluated the use of HDD to grout and seal the water-conducting overburden fractures (Figure 2). However, owing to an incomplete understanding of the development characteristics and grout hydraulic conductivity of the water-conducting overburden fractures exposed by the HDD, the grout sealing was difficult to implement, and no obvious sealing effectiveness was ultimately observed. Consequently, the test was suspended.

\subsection{Overview of Grouting and Water Blocking. The HDD} boreholes were designed to consist of identical vertical and build-up sections. After reaching the target horizons, the boreholes were advanced separately at each horizon in a "coordinated drilling-sealing" manner. That is, when the drilling fluid failed to return to the ground as the borehole 


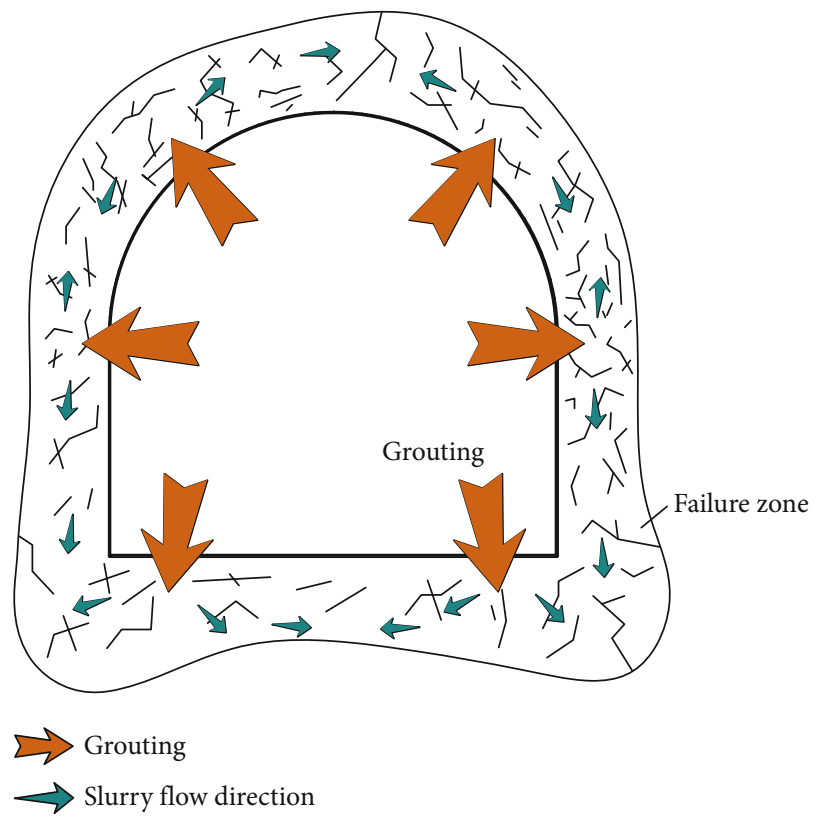

(a) Grouting in the surrounding rock fractures of a roadway

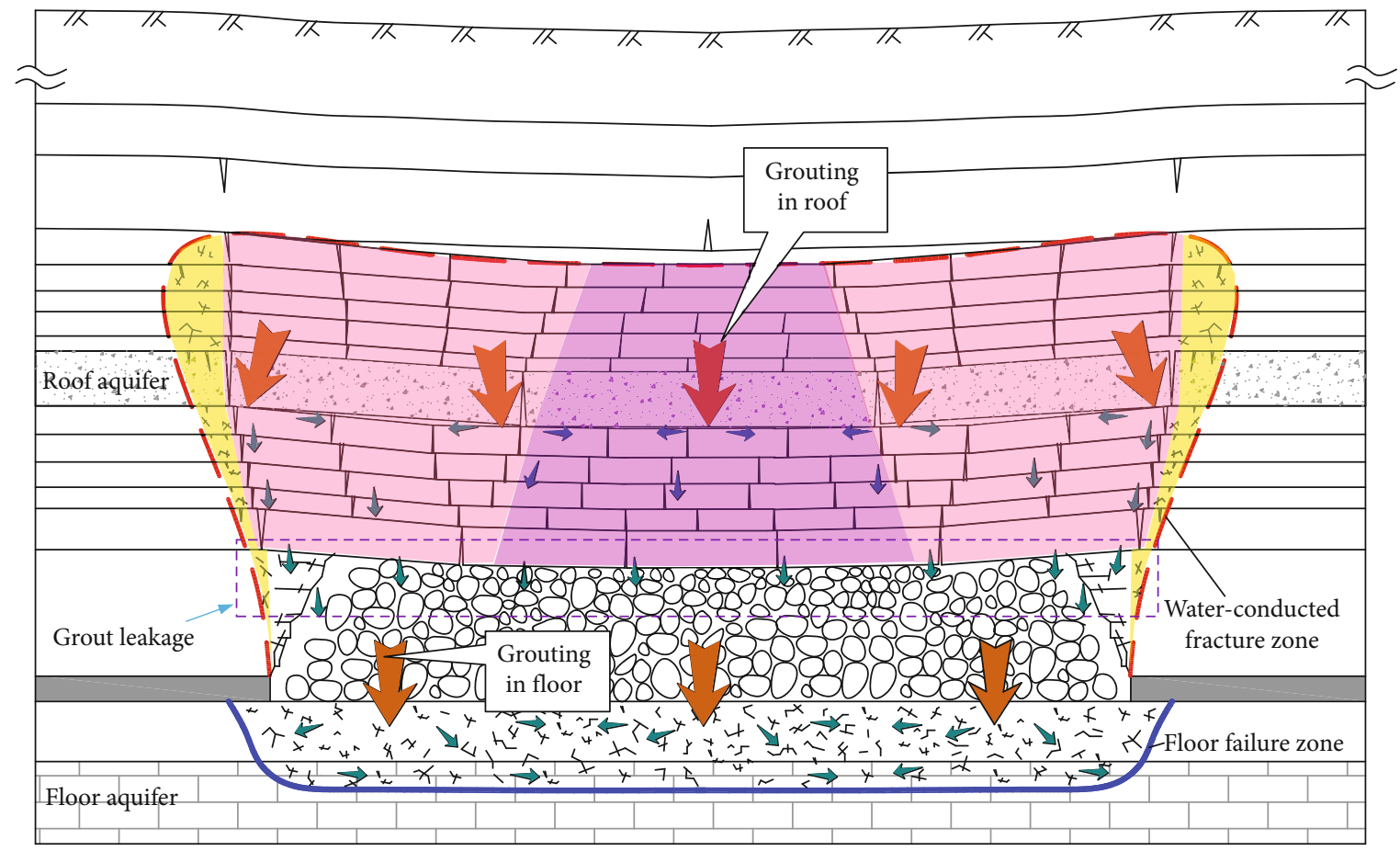

Compression shear fracture distribution area

Tensile fracture distribution area (open fracture)

Tensile fracture distribution area (closed fracture)

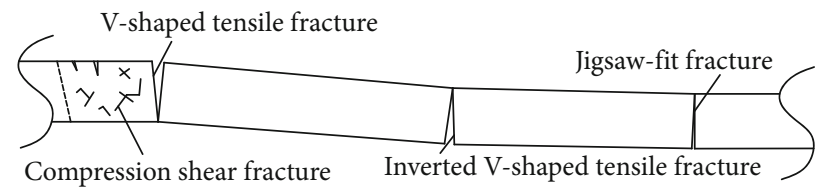

(b) Grouting in the roof and floor of a coal seam

FIGURE 1: Schematic diagram of grouting in the surrounding rock fractures of a roadway and the mining-induced roof and floor fractures of a coal seam. 


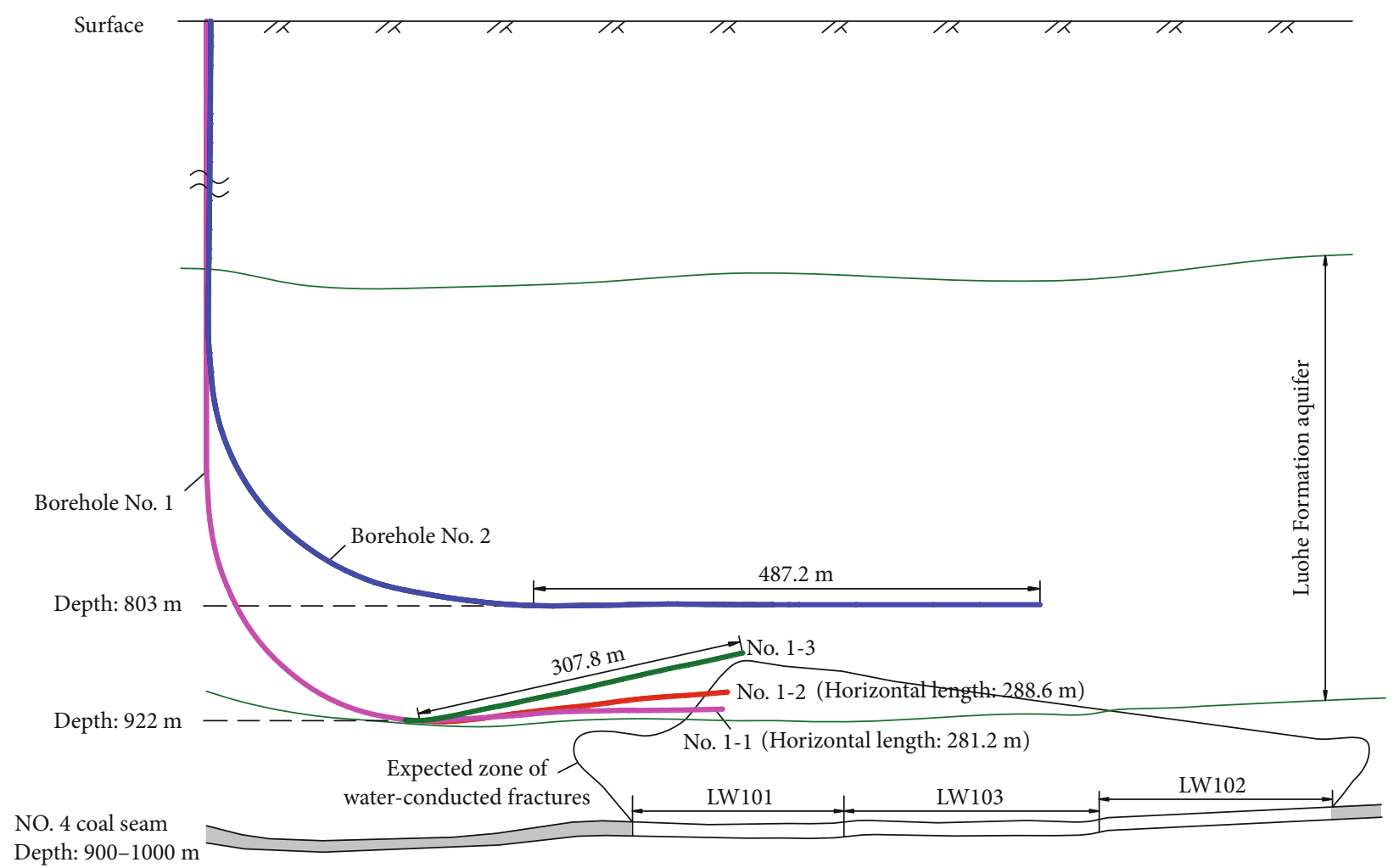

FIgURE 2: Trajectory of the HDD borehole in the Gaojiabao coal mine.

advanced (indicating that the borehole had exposed mininginduced fractures), drilling was immediately stopped, and grouting was implemented to seal the fractures. When the sealing proved effective, drilling was resumed. As mentioned in Introduction, when a borehole entered the predicted range of the water-conducting fracture zone (WCFZ) (Figure 2), drilling fluid was frequently lost, and grout sealing was required every $1.4-5.2 \mathrm{~m}$ of drilling distance. Various grouting materials were tested; however, the sealing performance was not satisfactory, and frequent leakage of those materials into the underground goaf or plugging of the borehole was observed. In particular, when cement, fly ash, clay, or other fine-grained materials were used for grouting, the grout did not remain in the fractures and directly leaked into the goaf. When using coarse-grained materials, such as walnut shells and cotton seeds, the boreholes were immediately plugged, and the grout was unable to be pumped into the fractures. As a result, the drilling horizons were adjusted on-site, and a total of four horizons were explored with two boreholes (Figure 2). For borehole 1, the vertical section was $630 \mathrm{~m}$ deep, and three horizontal sections, referred to as horizontal sections 1-1, 1-2, and 1-3, were explored. Horizontal section 1-1 was approximately $8 \mathrm{~m}$ above the bottom boundary of the Luohe Formation and $107 \mathrm{~m}$ above the top of the coal seam; horizontal section 1-2 was approximately $25 \mathrm{~m}$ above the bottom boundary of the Luohe Formation and $125 \mathrm{~m}$ above the top of the coal seam, and the highest point of horizontal section 1-3 was approximately $63 \mathrm{~m}$ above the bottom boundary of the Luohe Formation and $161.0 \mathrm{~m}$ above the top of the coal seam. Borehole 2 was a redrilled hole, spaced
$6 \mathrm{~m}$ from borehole 1 , that consisted of a $580 \mathrm{~m}$ deep vertical section and a horizontal section. The horizontal section was approximately $203 \mathrm{~m}$ above the top of the coal seam and $105 \mathrm{~m}$ above the bottom boundary of the Luohe Formation. An on-site test indicated that, although the intervals of grout sealing increased significantly after the adjustment of the drilling horizons (grout sealing was performed for every 7.9-44 m of drilling distance in borehole 2), it was still difficult to achieve sufficient fracture sealing, and there was no significant reduction in the inflow of water to the underground goaf.

As shown by the positions of the four horizontal sections relative to the range of the WCFZ in the overburden, grout sealing of the fractures tend to be difficult if the horizontal drilling was performed within the WCFZ or the curved subsidence zone above the WCFZ (i.e., the bed separation fracture distribution zone). It was evident that this difficulty was closely related to the development characteristics and grout hydraulic conductivity of the mining-induced overburden fractures exposed by the boreholes. Under current engineering conditions and with the given types of grouting materials, developing a method by which to determine a drilling trajectory and horizon favorable for the retention of grouting materials in mining-induced fractures is the key to solve this difficulty. To this end, the remainder of this study is focused on evaluating the grout hydraulic conductivity of the various types of water-conducting fractures exposed by HDD and exploring reasonable drilling horizons to provide a theoretical basis for improving the practical efficacy of using HDD borehole grouting to seal water-conducting overburden fractures. 


\section{Development Features of Mining-Induced Overburden Fractures Exposed by HDD}

3.1. Types of Mining-Induced Overburden Fractures. The formation of mining-induced overburden fractures is accompanied by the failure and movement of strata and the redistribution of stress in the rock mass. The strata in different regions may be subject to various stress conditions with different free space configurations, which can lead to different morphologies and development degrees (or apertures) in the fractures that ultimately affect the fracture conductivity. As shown in Figures 1 and 3, mining-induced fractures can be classified into three main types according to how they are formed. Type 1 fractures are tensile-shear fractures (i.e., break failure fractures) that are generated during the periodic break and rotation of strata. They exhibit a relatively uniform distribution in the overburden, with the horizontal spacing of such fractures in the same stratum being approximately equal to the broken step of the stratum. Type 2 fractures are shear fractures that are generated by the advanced abutment pressure in the coal-rock masses outside the mining boundaries. They are distributed in a disorderly manner and typically have a higher density than Type 1 fractures. Type 3 fractures are bed separation fractures that are generated during the uncoordinated movement of adjacent strata.

Type 1 fractures are also classified into three subtypes according to the location of the failed stratum in the overburden (Figure 3):

(a) V-shaped tensile fractures near the mining boundaries, which are generated when the stratum undergoes a single rotation with a clearly visible rotation angle

(b) Jigsaw-fit fractures in the central compacted zone of the mining area, which are generated when broken blocks of the strata undergo two rotations, each in an opposite direction (so there is no clearly visible rotation angle), and the fracture surfaces of adjacent broken blocks are pressed against each other. Although the fractures appear closed, the fracture surfaces cannot be fully fitted to each other owing to the differences in surface morphology and roughness. That is, the fractures still have a certain degree of aperture and flow conductivity

(c) Inverted $\mathrm{V}$-shaped tensile fractures between the mining boundaries and central compacted zone, which are generated by two adjacent broken blocks with different rotation angles

Type 3 fractures have a similar distribution pattern to Type 1. That is, bed separation fractures are open near the mining boundaries where the fracture void volume is relatively large and are closed in the central compacted zone.

As shown above, fractures in different areas of the overburden will have different morphologies and development degrees (or apertures) when the overlying strata are in various stress states with different movement characteristics. When HDD is directed from the original rock mass outside the mining area towards the fractured rock mass in the mining-affected area, the various fracture types will be successively exposed at different positions. Moreover, the distribution pattern of the exposed fractures will vary at different drilling horizons. All these factors will ultimately affect the diffusion and flow behavior of the grout and the sealing results of the fractures.

\subsection{Simulation Experiment of HDD to Expose Mining- Induced Overburden Fractures}

3.2.1. Experimental Scheme. A simplified experimental set-up was constructed using the $2.5 \mathrm{~m}$ long physical model frame shown in Figure 4(a) with consideration for the strata conditions of the No. 1 panel of the Gaojiabao coal mine. To simulate HDD and demonstrate the morphology of the borehole-exposed fractures in a straightforward manner, the model was installed in one half of the model frame, while the drilling process was simulated in the other half. A borehole observation instrument was deployed onsite to photograph the exposed fractures inside the borehole. The physical model had dimensions of $1.2 \mathrm{~m}$ (length) $\times 1 \mathrm{~m}($ height $) \times 0.2 \mathrm{~m}$ (width). The geometric similarity ratio of the set-up was $1: 100$, the stress similarity ratio was $1: 125$, and the density similarity ratio was $1: 1.25$. The similar material proportions of the physical model for each stratum are listed in Table 1. Coal seam excavation advanced from the left side of the model towards the right side, and $5 \mathrm{~cm}$ wide protective coal pillars were reserved at each of the two mining boundaries of the model.

3.2.2. Experimental Results. As shown by the sketch in Figure 5 of the overburden failure and fracture development after the coal seam was completely excavated, a waterconducting fracture propagated to the bottom boundary of the third overlying stratum, which was a key stratum (KS). The corresponding WCFZ had a height of $43 \mathrm{~m}$. An electric drill was used to simulate HDD from the left side of the model towards the mining-induced fracture area, while a drill TV was used to photograph the morphologies of the different types of fractures exposed by the borehole, as shown in Figure 3. As the physical model was unable to simulate compressive shear fractures outside the mining boundary, no corresponding photos were taken during the drilling simulation. The results showed that, when exposed by the borehole, the fractures manifested as voids of different scales as a result of their varying apertures. The aperture differences of the exposed fractures varied with the drilling horizons. These characteristics directly affected the flow behavior and sealing performance of the injected grout. Therefore, the types and apertures (or void size) of the borehole-exposed fractures at the different drilling horizons were statistically analyzed. A total of six survey lines were set as shown in Figure 5. In particular, survey lines L1 and L2 were outside the WCFZ but inside KS 3, while the other survey lines were all within the WCFZ and ran through different strata, resulting in a "multi-stratum run-through" phenomenon.

Figure 6 shows the distribution of the fracture types and apertures exposed at the different horizons. To facilitate 


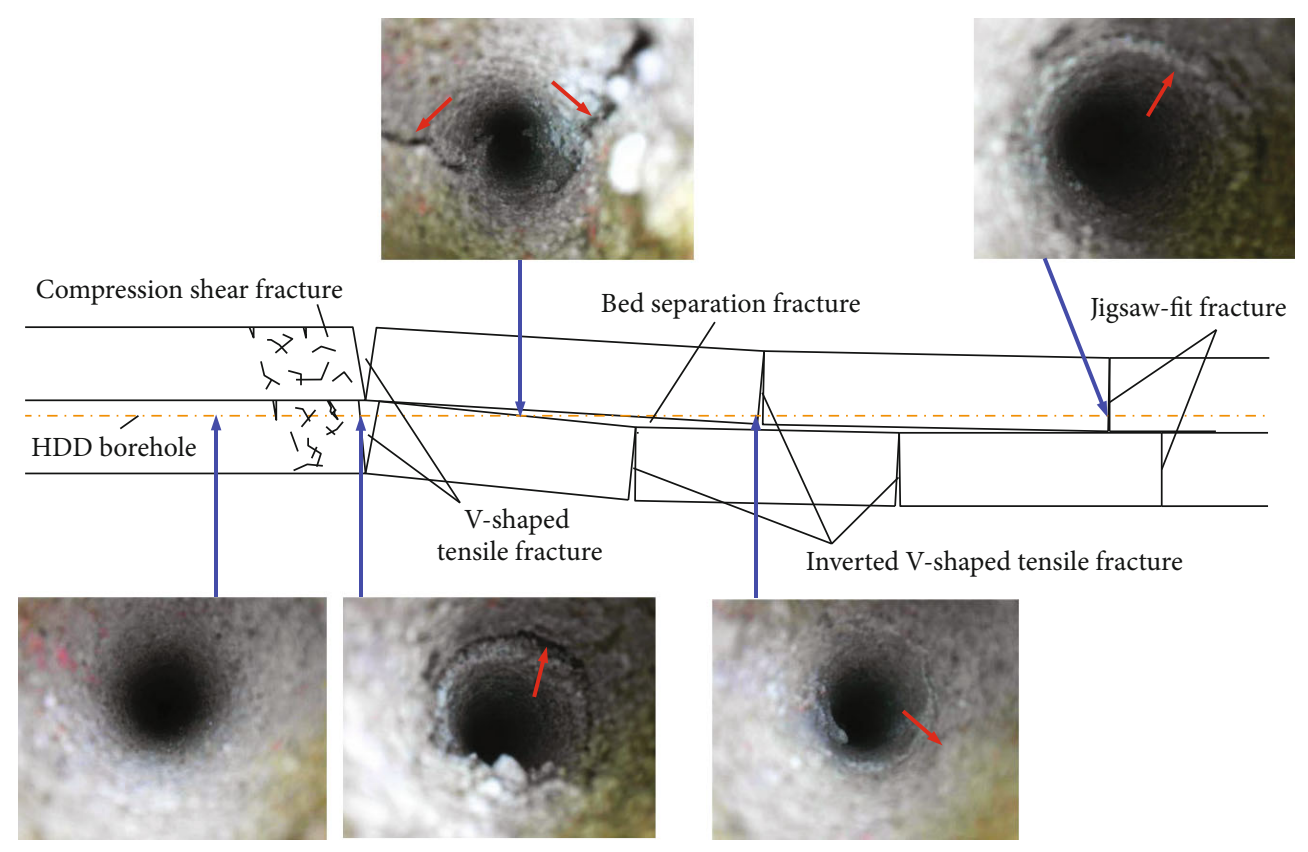

FIgURe 3: Types of mining-induced fractures exposed by HDD. Note: the photos are of the fractures exposed by the simulated borehole created in the physical simulation discussed in Section 3.2.

calibration and distinction, the different types of fractures in the stratum where a survey line was made, as well as in the adjacent (upper and lower) strata, were numbered. "A" represented the failure fractures in a given stratum and was divided into three subtypes: A-1, representing V-shaped tensile fractures in the stratum; A-2, representing inverted Vshaped tensile fractures in the stratum; and A-3, representing jigsaw-fit fractures in the stratum. " $\mathrm{B}$ " and " $\mathrm{C}$ " represented failure fractures in the adjacent strata above and below, respectively, and were each divided into three subtypes (namely, B-1, B-2, and B-3 and C-1, C-2, and C-3) to represent $\mathrm{V}$-shaped tensile fractures, inverted $\mathrm{V}$-shaped tensile fractures, and jigsaw-fit fractures, respectively. "D" represented the bed separation fractures between adjacent strata.

The six survey lines revealed that, as the drilling horizon was lowered, the number of exposed mining-induced fractures increased, and their apertures widened. Survey lines L1 and L2 were outside the WCFZ and only revealed three break failure fractures with small apertures in KS 3. In contrast, the other four survey lines below KS 3 ran through different strata, and each revealed bed separation fractures with unusually large fracture apertures (or void sizes) when in proximity to the bottom boundary of the KS. On survey line L3, for example, which was $3 \mathrm{~cm}$ below the bottom boundary of the KS, the voids in the bed separation fractures had a total length of $180.72 \mathrm{~mm}$. Considering the geometric similarity ratio of the simulation model, this data suggested that, when drilling in this stratum, the borehole would advance $18 \mathrm{~m}$ into the delamination space before it entered the rock mass. In other words, such a void would need to be grouted and sealed to avoid the loss of drilling fluid and indicates a significant increase in the difficulty of using borehole grouting to seal fractures. Similarly, survey lines near the mining boundaries revealed significantly large voids in the $\mathrm{V}$-shaped tensile fractures or inverted V-shaped tensile fractures. For example, survey line L5 near the right mining boundary revealed that the aperture of the $\mathrm{V}$-shaped tensile fractures was as wide as $6 \mathrm{~mm}$, equating to an exposed void width of $0.6 \mathrm{~m}$ in practical drilling operations. A similar observation was made for survey line L6, which was about $50 \mathrm{~cm}$ from the left mining boundary and revealed an aperture of approximately $3.5 \mathrm{~mm}$ in the inverted $\mathrm{V}$-shaped tensile fractures.

These observations explain the extreme difficulty associated with using HDD borehole grouting to seal waterconducting fractures that was experienced in the engineering test in the Gaojiabao coal mine. Essentially, owing to the large voids in the break tensile fractures and bed separation fractures that were frequently exposed by the boreholes, it was difficult to retain the injected grout, which was the main cause of the difficulty associated with grout sealing the fractures. Setting a proper drilling horizon and trajectory according to the grout hydraulic conductivity of the various types of fractures is the key to overcome this difficulty.

\section{Types of Fractures Exposed by the HDD Boreholes and Their Grout Hydraulic Conductivity}

4.1. Grout Hydraulic Conductivity. As indicated by the observed distribution pattern of the fracture apertures on the different survey lines in the simulation experiment, when HDD was performed from outside the mining area into the mining overburden, the different types of fractures were exposed in one of the following orders depending on the drilling horizon.

4.1.1. Order I. The borehole advanced in a single stratum within the WCFZ (Figure 7(a)). During drilling, the fractures 


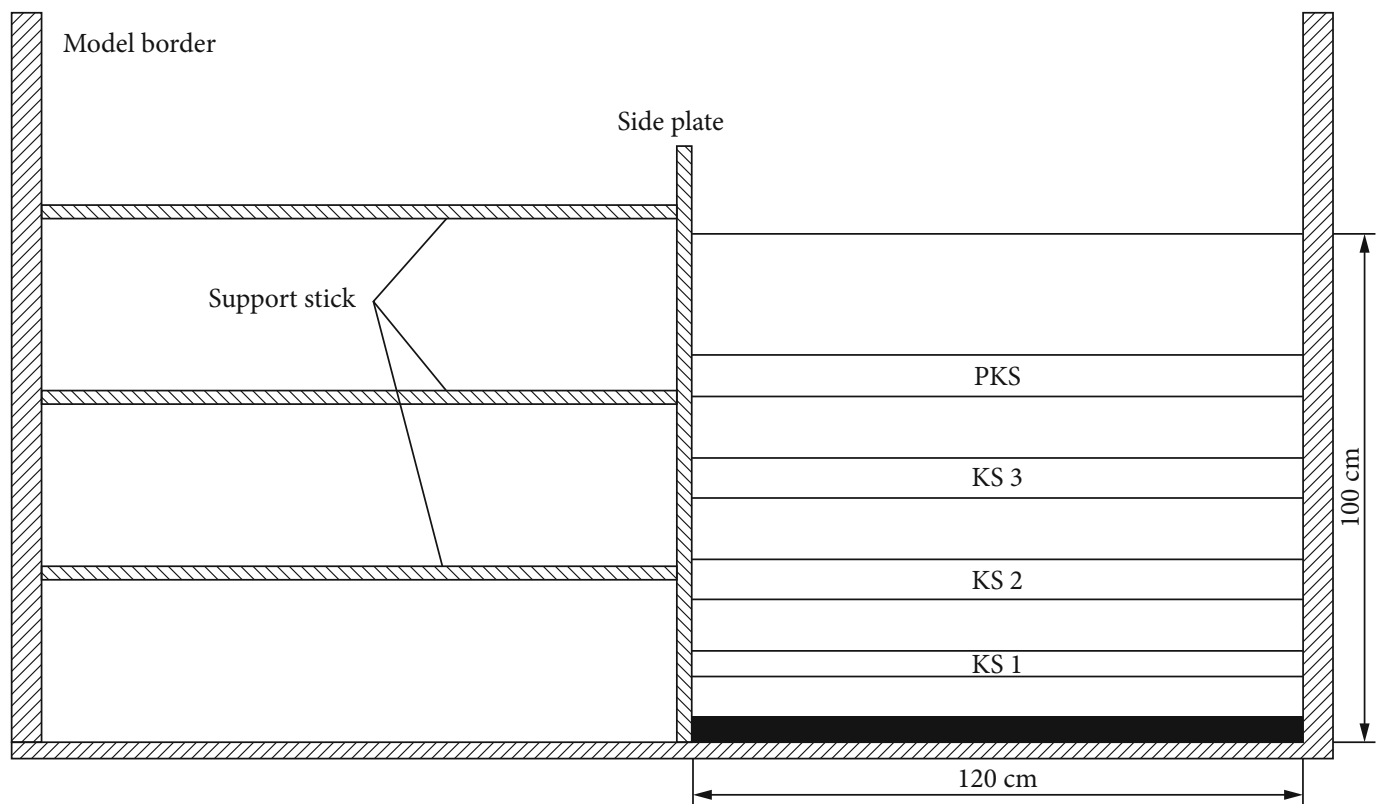

(a) Model layout
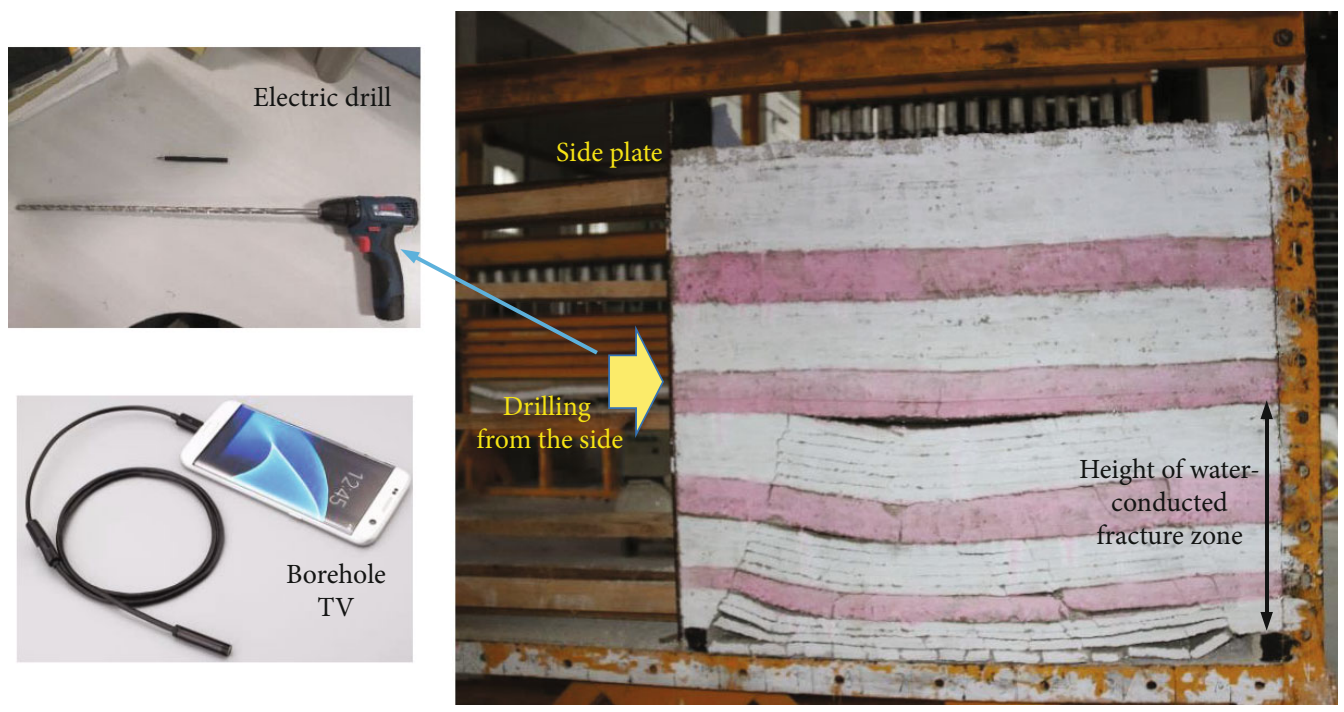

(b) Physical photos

Figure 4: Physical simulation model.

TABLE 1: Similar material proportion for each stratum.

\begin{tabular}{lcccc}
\hline Strata & Thickness/cm & Sand $/ \mathrm{kg}$ & Calcium carbonate $/ \mathrm{kg}$ & Gypsum $/ \mathrm{kg}$ \\
\hline Soft strata & 24 & 69.2 & 12.10 & 2.16 \\
Primary key stratum (PKS) & 8 & 21.6 & 6.05 & 5.20 \\
Soft strata & 12 & 34.6 & 1.73 & 2.04 \\
KS 3 & 8 & 23.04 & 2.60 & 4.03 \\
Soft strata & 12 & 34.6 & 1.73 & 6.05 \\
KS 2 & 8 & 23.04 & 5.04 & 4.03 \\
Soft strata & 10 & 28.8 & 1.08 & 2.16 \\
KS 1 & 5 & 14.4 & 4.02 & 2.52 \\
Soft strata & 8 & 23.04 & 1.58 & 0.675 \\
Coal seam & 5 & 15.8 & & 1.73 \\
\hline
\end{tabular}




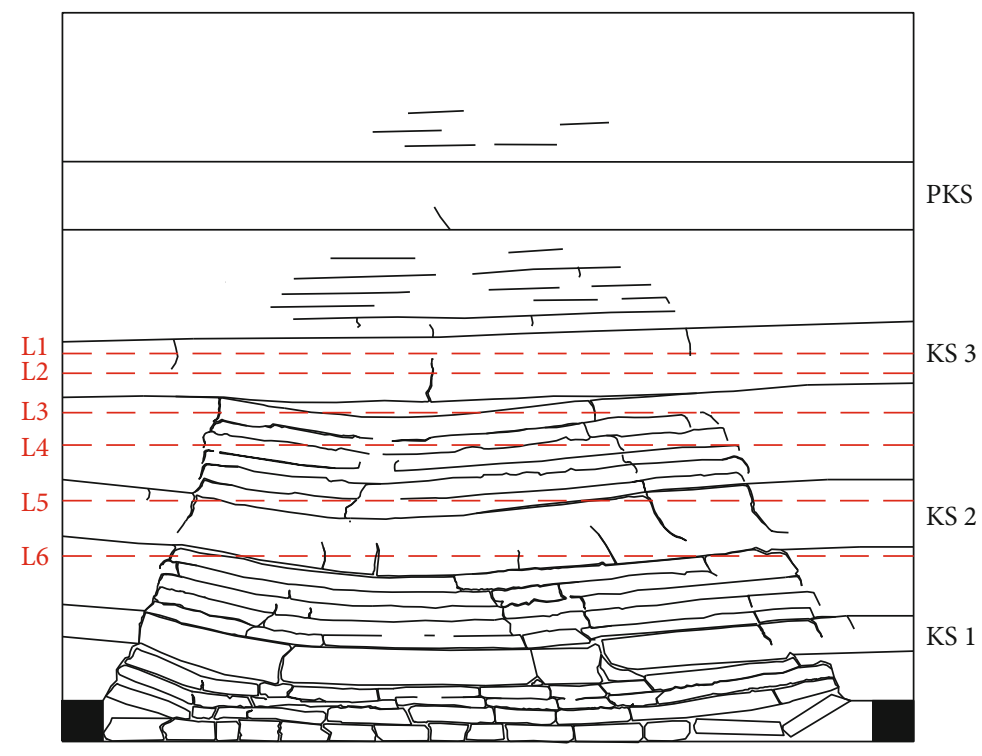

FIGURE 5: Sketched simulation results of the overburden failure.

were exposed in the following order: compressive shear fractures $\rightarrow \mathrm{V}$-shaped tensile fractures $\rightarrow$ inverted V-shaped tensile fractures $\rightarrow$ jigsaw-fit fractures. Then, as the borehole continued to advance toward another mining boundary, the fractures were exposed in the opposite order. This exposure order is often observed when drilling through a thick stratum, and the drilling distance between two consecutive rounds of drilling fluid loss and grout sealing was close to the broken step of the stratum.

When compressive shear fractures were exposed by the borehole, it was easy to conduct grout sealing with a low risk of grout escape owing to the small fracture apertures and poor fracture connectivity $[19,20]$. In this scenario, finegrained grouting materials, such as fly ash, cement, and water glass, are preferred. When V-shaped tensile fractures were exposed in a stratum, owing to their numerous voids and the fact that the fractures were often connected to other Vshaped tensile fractures in the lower adjacent stratum, it was advisable to first inject a coarse-grained grout until the channel connecting the lower V-shaped tensile fractures was sealed. Then, a large volume of fine-grained grout could be injected. The grout in an exposed fracture void will gradually accumulate upward only after it has flowed to its diffusion radius in the void, and the accumulation will continue until the grout reaches the drilling horizon and seals the fracture openings on the borehole wall [21]. Only after sealing is complete can drilling be resumed and continued smoothly (Figure 8). Therefore, horizontal drilling at various distances from the bottom boundary of a stratum leads to significantly different grouting volumes. The closer the drilling horizon is to the bottom boundary of the stratum, the smaller the exposed fracture opening and the lower the required volume of grout for sealing. Drilling is then resumed and continued until inverted V-shaped fractures are exposed. Inverted Vshaped fractures are connected to bed separation fractures and, thus, have a larger void volume which requires more grout than V-shaped fractures. Consequently, drilling can only resume once the grout flows to its diffusion radius in the bed separation fractures and gradually accumulates at the drilling horizon. As the borehole advances, it will expose jigsaw-fit fractures. Although the exposed jigsaw-fit fractures are often connected to lower bed separation fractures or jigsaw-fit fractures in the adjacent stratum, they have small apertures and are easy to seal. This allows for the use of an easily solidifiable fine-grained grout to seal the fractures, which enables quick resumption of drilling. It should be noted that the size (i.e., diameter) of the borehole is significantly smaller than that of the $\mathrm{V}$-shaped tensile apertures or delamination apertures, and coarse-sized grout is prone to plugging the boreholes. This results in a dilemma where although the grouting pressure is high, the fractures are not actually sealed. Therefore, when grouting and sealing fractures with large apertures or voids, it is necessary to increase the diameter of the borehole or reduce the grout injection flow rate to reduce the risk of borehole plugging.

4.1.2. Order II. Horizontal drilling proceeds through different strata within the WCFZ (Figure 7(b)) and exposes fractures in the following order: compressive shear fractures $\rightarrow \mathrm{V}$ shaped tensile fractures (in the same stratum) $\rightarrow$ bed separation fractures $\rightarrow$ inverted V-shaped tensile fractures (in the upper adjacent stratum) $\rightarrow$ jigsaw-fit fractures (in the upper adjacent stratum). The exposure order is reversed as the borehole continues to advance toward the other mining boundary. Drilling proceeded through different strata in Order II to allow the exposure of additional bed separation fractures near the mining boundaries, thereby making the drilling distance between two consecutive rounds of drilling fluid loss and grout sealing shorter than in the case of Order I. Due to the breaking and rotation of the strata, in practical drilling operations, HDD in the mining overburden inevitably leads to the "multi-stratum run-through" phenomenon. As a result, Order II is the most commonly adopted method in practice. 


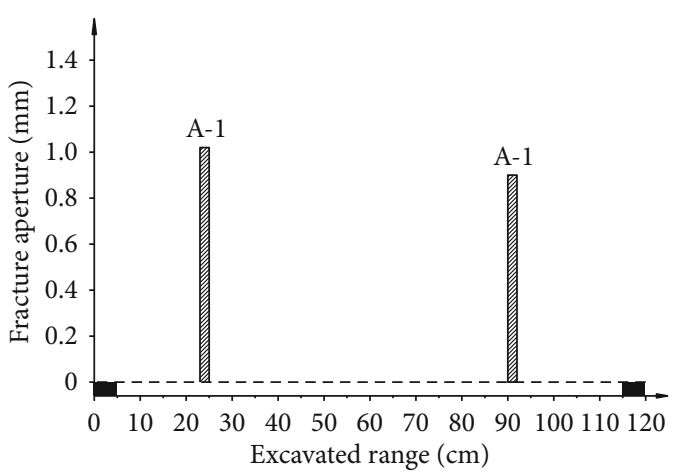

(a) Line L1

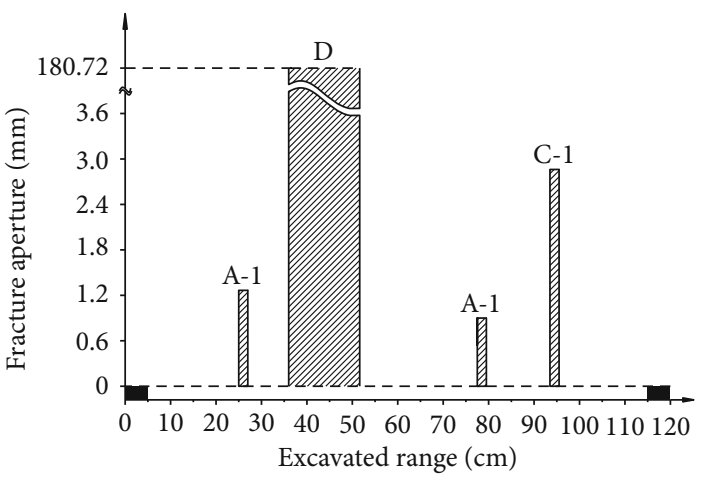

(c) Line L3

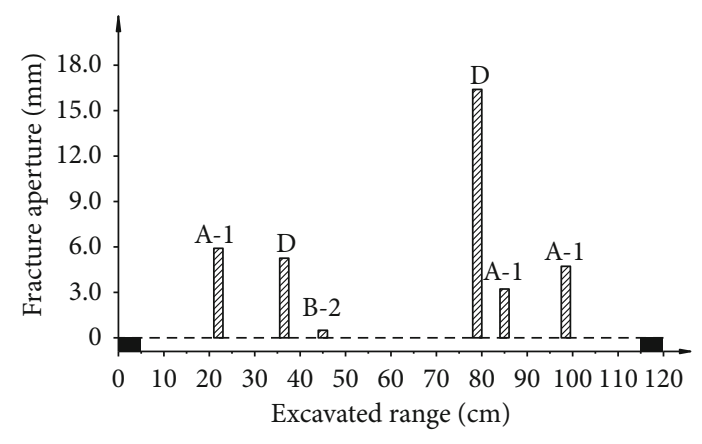

(e) Line L5

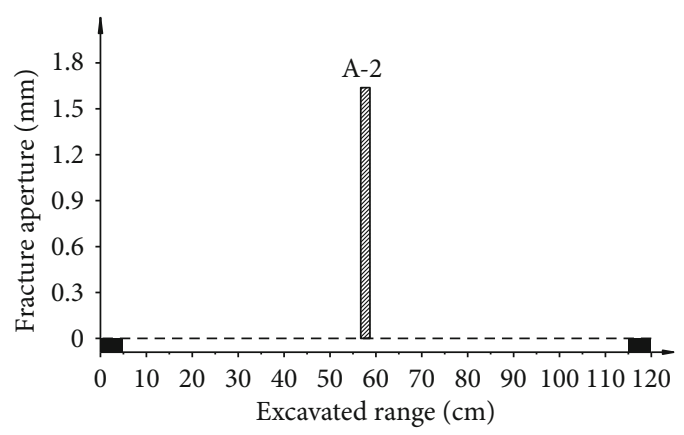

(b) Line L2

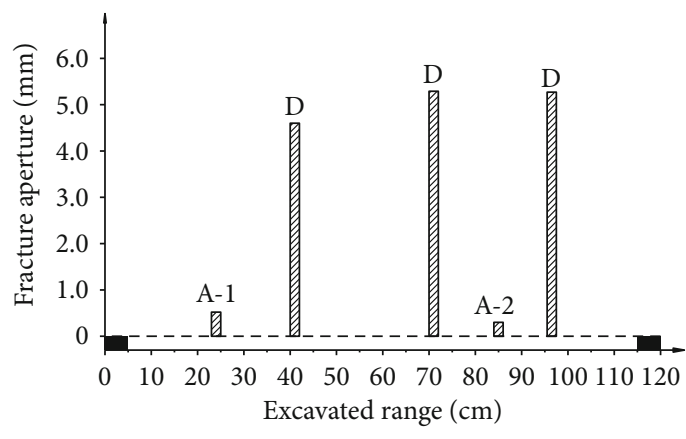

(d) Line L4

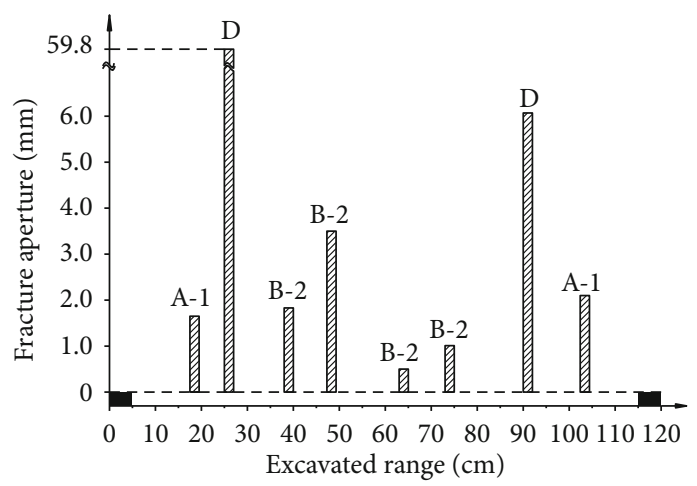

(f) Line L6

FIgURE 6: Distribution of the types and apertures of the mining-induced fractures at different horizons.

As the HDD borehole advances to expose bed separation fractures, the size of the voids in the drilling direction increases sharply. Thus, it is appropriate to use coarsegrained materials for grout sealing in this situation. Moreover, it is necessary to continuously grout the fractures while the grout flows to its horizontal diffusion radius and accumulates upward. When the grout reaches the drilling horizon, grouting could be stopped, and drilling could be resumed. As bed separation fractures are often connected to inverted $\mathrm{V}$-shaped tensile fractures in the upper adjacent stratum (Figure $7(\mathrm{~b})$ ), the degree of grout sealing in the bed separation fractures (namely, the diffusion range and accumulation height of the grout) will affect the difficulty of sealing the inverted V-shaped tensile fractures next exposed by the drilling. The higher the degree of sealing in the bed separation fractures and the greater the diffusion range of the grout, the smaller the required grouting volume will be to seal the inverted V-shaped fractures. As bed separation fractures are caused by the uncoordinated movement of two vertically adjacent strata, it is evident that bed separation fractures in the presence of a thicker and harder upper stratum (such as the KS) will exhibit a significantly higher void volume than those in the presence of a thinner and softer upper stratum. In addition, with a decrease in the rotation angles of the broken strata, the drilling distance in the delamination space will increase, leading to a larger grouting volume and higher sealing difficulty. Therefore, it is necessary to consider the conditions of the drilled strata in practical drilling operations in order to select proper grouting materials and volumes.

4.1.3. Order III. Drilling is performed in the curved subsidence zone outside the WCFZ (Figure 7(c)), and the borehole 


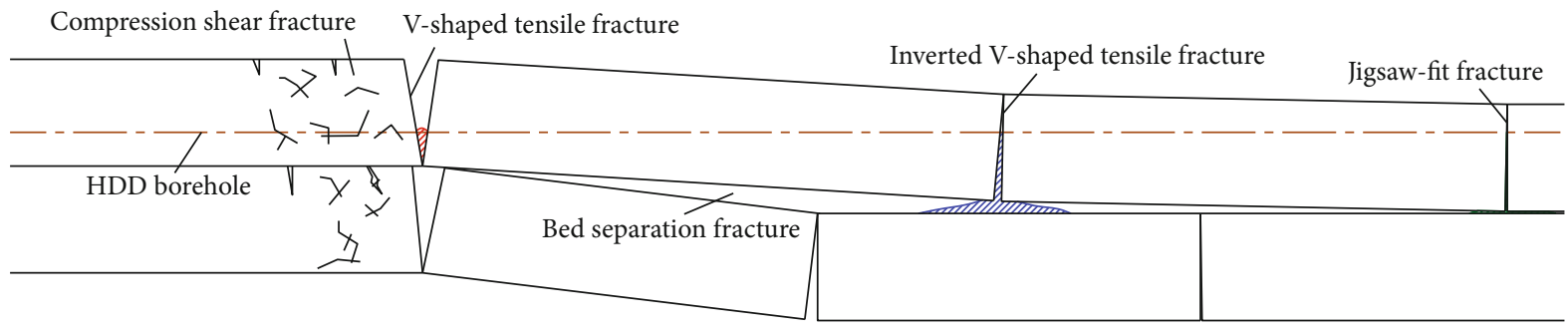

(a) Order I

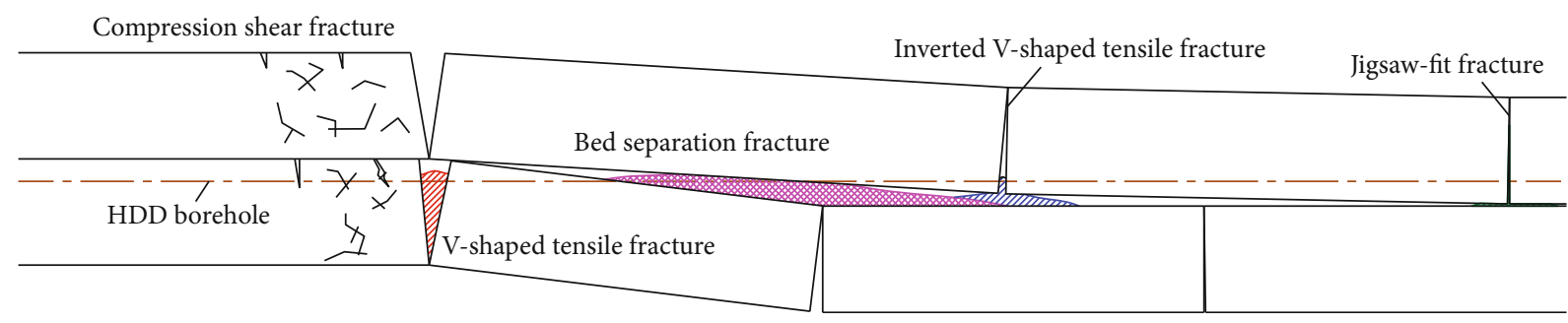

(b) Order II

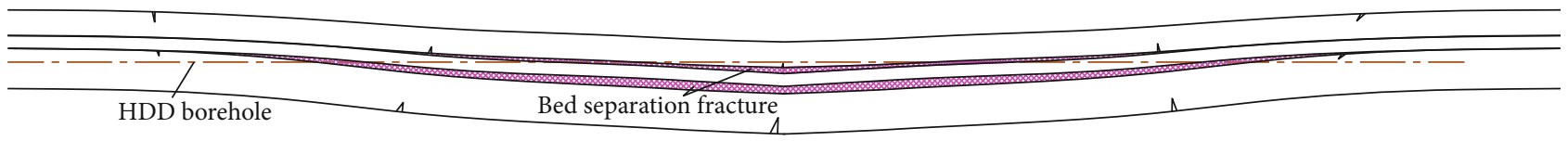

(c) Order III

Figure 7: Types of fractures exposed by the HDD boreholes at different horizons.

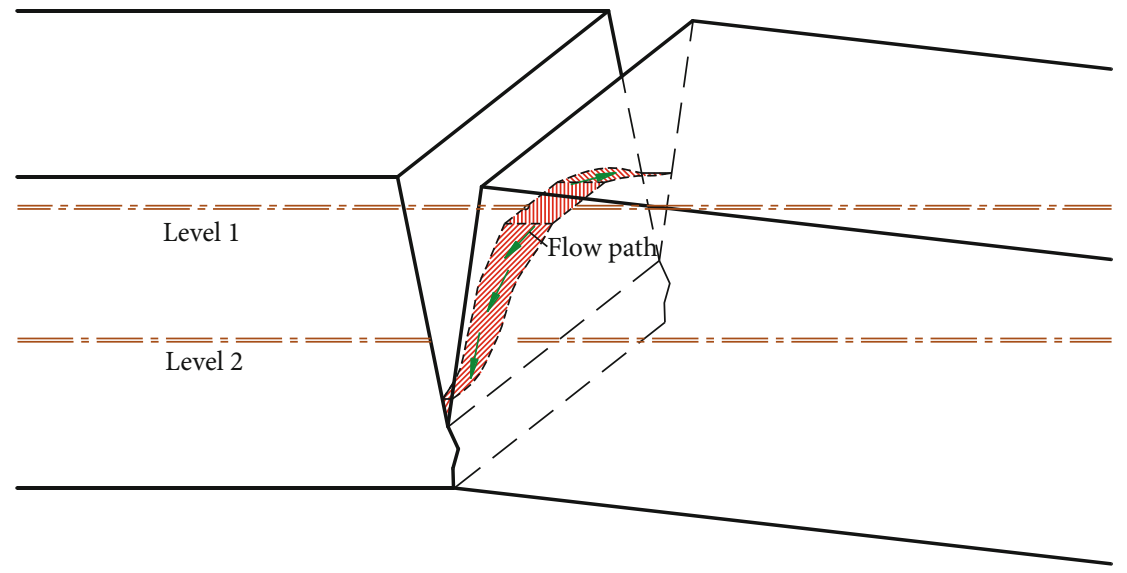

FIGURE 8: Schematic diagram of grouting the V-shaped tensile fractures exposed by HDD.

advances through different strata to expose bed separation fractures.

In contrast to the borehole-exposed bed separation fractures in the WCFZ in Order II, the bed separation fractures in the curved subsidence zone in Order III have a relatively closed space. Thus, they are suitable for grouting with a large volume of fine-grained materials and have a low risk of grout escape. As the rotation angles of the strata in the curved subsidence zone are relatively small, the borehole needs to advance a significant distance in the delamination fracture before entering the upper adjacent stratum. This results in high grouting volume and frequency in practice. Once the borehole enters the upper adjacent stratum, it needs to advance a significant distance before exposing another delamination fracture where frequent grout sealing will again be required. Therefore, the frequency of grout sealing will alternate between high and low as the borehole advances, such as the case with the drilling of borehole 2 in the Gaojiabao coal mine. However, it should be noted that only the bed separation fractures in the curved subsidence zone are grouted and sealed in such a case, and it is impossible to achieve water blocking in practice. Ultimately, the bed separation fractures in the curved subsidence zone do not constitute a channel that leads to groundwater loss. This is in line with the observation that the influx of underground water into the Gaojiabao coal mine did not significantly decrease after the large-scale grouting of borehole 2 in the water blocking test. 
4.2. Determination of Reasonable Drilling Horizons for Efficient Fracture Sealing. As previously shown, when using HDD borehole grouting to seal water-conducting overburden fractures while minimizing the grouting volume, it is exceedingly important to determine the reasonable drilling horizon in a scientific manner. Selection of the HDD horizons should be based on the following three principles.

(1) Borehole grouting is intended to seal the waterconducting channels that lead to groundwater loss. Therefore, it is necessary to ensure that the drilling horizon is within the WCFZ of the mining overburden

(2) The fractures exposed at the drilling horizon should have good capacity to retain the grout. In other words, the injected grout should remain within the fracture voids to seal the fractures without the risk of grout escape. Therefore, it is best to drill at horizons where the fracture apertures are small. It is also necessary to ensure that the vertical connectivity between the exposed fractures and the fractures in the lower stratum is as small as possible in order to avoid grout leakage to the underground goaf. In the meantime, it is necessary to increase the grout diffusion in the plane to increase the range of the grout sealing within a single borehole. Generally, the higher the borehole horizon, the smaller the aperture of the exposed mining-induced fractures. However, drilling may be performed under but near the bottom boundary of a thick, hard stratum (such as the KS) to expose large voids in the bed separation fractures, such as the voids shown on survey line L3 in Figures 5 and 6. On the one hand, proper selection of the drilling horizons would improve the planar diffusion range of the grout. On the other hand, since bed separation fractures are typically connected to multiple tensile fractures in the lower stratum, such selection would increase the risk of grout loss in the vertical direction. Therefore, full consideration should be given to the planar distribution characteristics of mininginduced fractures in order to comprehensively evaluate the planar diffusion of the grout in the fractures. This should then be compared to the risk of grout loss in the vertical direction in order to determine the most suitable horizon

(3) The drilling horizon should be favorable for maintaining the stability of the drilled rock mass. An HDD borehole mainly consists of a vertical section, build-up section, and horizontal section. Both the vertical and build-up sections are lined and protected by a casing, while the horizontal section is unlined. If the horizontal section is drilled in a stratum with relatively weak lithology, there is a high risk of hole collapse due to mining-induced fractures. These types of accidents will affect the grouting procedure and water blocking performance. Therefore, it is necessary to set the drilling horizon in a stratum (e.g., sandstone) with stable lithology and high mechanical strength according to the stratigraphic column of the overburden

According to these principles, it is possible to determine a reasonable borehole horizon for the HDD in the overburden with consideration for the overburden conditions presented by the physical simulation results and distribution of the water-conducting fractures (Figure 5). As the WCFZ extended vertically up to the bottom boundary of KS 3 , the drilling horizon should be set below this stratum. Survey lines L3-L6 were all within the WCFZ; however, as shown in Figure 6, the fracture aperture on survey line L4 was the minimum (although survey line L3 was at a higher horizon, it ran through bed separation fractures; thus, revealing larger void volumes). Therefore, if a stable sandstone stratum was present near L4, it would serve as a suitable drilling horizon.

\section{Conclusions}

(1) A ground-based engineering test was conducted in the Gaojiabao coal mine to evaluate the use of HDD to grout and seal water-conducting fractures; however, the water blocking performance was not satisfactory. The present study utilized HDD boreholes to expose the development characteristics and grout hydraulic conductivity of water-conducting fractures and determined reasonable drilling trajectories or horizons favorable for grout sealing of the fracture channels, which are the keys to solving these problems

(2) As a horizontal directional borehole advances from the original rock mass outside the mining boundary towards the mining-induced fractured rock mass, the borehole will successively expose fractures with different development morphologies. The order of exposure was found to be dependent on the drilling horizon and whether the borehole runs through different strata. A simulation experiment was conducted and revealed three orders in which the various types of mining-induced fractures could be exposed by an HDD borehole. When using HDD boreholes to expose different types of mining-induced fractures and seal them with grout, each type of fracture will exhibit different grout hydraulic conductivity as a result of their varying void volumes and scales, which explains why the frequent grout sealing conducted in the engineering test resulted in such poor sealing performance

(3) The capacity of the mining-induced fractures to retain grout was investigated, and further analysis of the results led to a scheme for determining reasonable horizons for HDD to facilitate efficient fracture sealing. The drilling horizon should be selected in such a way that the apertures of the boreholeexposed fractures are as small as possible, and the vertical connectivity of the borehole-exposed fractures to fractures in the lower stratum should also be as small as possible. This would reduce the risk 
of grout escape in the vertical direction while enhancing the planar hydraulic conductivity of the grout. This scheme is intended to ultimately determine the achievable range of grout sealing for a single borehole while attaining the grout sealing of as many fractures as possible with as small a grouting volume as possible

(4) Except for the fracture morphologies, the high flowrate of water is also an important factor that prevented the grout from accumulating in and filling up the fractures, especially, for the readily hardenable grout such as cement. In addition, when sealing with different grout types, the influence degree of hydrodynamic erosion on the sealing effect may be different. Owing to limited space, the abovementioned factor was not discussed in the paper, and further research will be carried out in the future

\section{Data Availability}

The data used to support the finding of this study are available from the corresponding author upon request.

\section{Conflicts of Interest}

The authors declared that they have no conflicts of interest to this work.

\section{Acknowledgments}

Financial support from the Fundamental Research Funds for the Central Universities (2020ZDPYMS19) is greatly appreciated.

\section{References}

[1] J. C. Zhang and B. H. Shen, "Coal mining under aquifers in China: a case study," International Journal of Rock Mechanics and Mining Sciences, vol. 41, no. 4, pp. 629-639, 2004.

[2] X. X. Miao, X. M. Cui, J. A. Wang, and J. L. Xu, "The height of fractured water-conducting zone in undermined rock strata," Engineering Geology, vol. 120, no. 1-4, pp. 32-39, 2011.

[3] J. L. Xu, Green Mining in Coal Mines, China University of Mining and Technology Press, Xuzhou, China, 2011.

[4] J. F. Ju, J. L. Xu, Q. S. Li, W. B. Zhu, and X. Z. Wang, "Progress of water-preserved coal mining under water in China," Coal Science and Technology, vol. 46, no. 1, pp. 12-19, 2018.

[5] H. Lisa, B. Christian, F. Asa, G. Gunnar, and F. Johan, "A hard rock tunnel case study: characterization of the water-bearing fracture system for tunnel grouting," Tunnelling and Underground Space Technology, vol. 30, pp. 132-144, 2012.

[6] A. H. Hoien and B. Nilsen, "Rock mass grouting in the Løren tunnel: case study with the main focus on the groutability and feasibility of drill parameter interpretation," Rock Mechanics and Rock Engineering, vol. 47, no. 3, pp. 967-983, 2014.

[7] S. C. Li, R. T. Liu, Q. S. Zhang, and X. Zhang, "Protection against water or mud inrush in tunnels by grouting: a review," Journal of Rock Mechanics and Geotechnical Engineering, vol. 8, no. 5, pp. 753-766, 2016.
[8] J. F. Ju and J. L. Xu, Damage Mechanisms of Aquifers Induced by Underground Coal Mining and its Ecological Restoration, China University of Mining and Technology Press, Xuzhou, China, 2019.

[9] I. F. Oge, "Prediction of cementitious grout take for a mine shaft permeation by adaptive neuro-fuzzy inference system and multiple regression," Engineering Geology, vol. 228, pp. 238-248, 2017.

[10] J. Chai, Q. Yuan, S. Wang et al., "Water inrush control and restoration of shaft construction in cretaceous aquifer," Journal of China Coal Society, vol. 41, no. 2, pp. 338-344, 2016.

[11] H. Shimada, A. Hamanaka, T. Sasaoka, and K. Matsui, "Behaviour of grouting material used for floor reinforcement in underground mines," International Journal of Mining, Reclamation and Environment, vol. 28, no. 2, pp. 133-148, 2014.

[12] B. T. Shen, "Coal mine roadway stability in soft rock: a case study," Rock Mechanics and Rock Engineering, vol. 47, no. 6, pp. 672225-672238, 2014.

[13] F. Zhou, W. B. Sun, J. L. Shao, L. J. Kong, and X. Y. Geng, "Experimental study on nano silica modified cement base grouting reinforcement materials," Geomechanics and Engineering, vol. 20, no. 1, pp. 67-73, 2020.

[14] Z. P. Xu, C. W. Liu, X. W. Zhou, G. R. Gao, and X. H. Feng, "Full-scale physical modelling of fissure grouting in deep underground rocks," Tunnelling and Underground Space Technology, vol. 89, pp. 249-261, 2019.

[15] S. Q. Liu, Y. Fei, Y. C. Xu, L. Huang, and W. Y. Guo, "Full-floor grouting reinforcement for working faces with large mining heights and high water pressure: a case study in China," Mine Water and the Environment, vol. 39, no. 2, pp. 268-279, 2020.

[16] W. Q. Zhu, X. X. Zhu, S. X. Xu, Z. Y. Wang, and W. Li, “Experimental study on properties of a new type of grouting material for the reinforcement of fractured seam floor," Journal of Materials Research and Technology, vol. 8, no. 6, pp. 5271$5282,2019$.

[17] G. Y. Li and W. F. Zhou, "Impact of karst water on coal mining in North China," Environmental Geology, vol. 49, no. 3, pp. 449-457, 2006.

[18] Z. G. Cao, J. F. Ju, and J. L. Xu, "Distribution model of waterconducted fracture main channel and its flow characteristics," Journal of China Coal Society, vol. 44, no. 12, pp. 3719-3728, 2019.

[19] L. Sun, G. Grasselli, Q. S. Liu, and X. H. Tang, "Coupled hydromechanical analysis for grout penetration in fractured rocks using the finite-discrete element method," International Journal of Rock Mechanics and Mining Sciences, vol. 124, p. $104138,2019$.

[20] H. M. Kim, J. W. Lee, M. Yazdani, E. Tohidi, H. R. Nejati, and E. S. Park, "Coupled viscous fluid flow and joint deformation analysis for grout injection in a rock joint," Rock Mechanics and Rock Engineering, vol. 51, no. 2, pp. 627-638, 2018.

[21] X. C. Wang, R. T. Liu, W. M. Yang et al., "Study on grouting mechanism of horizontal fractures considering the bleeding of cement slurry," Chinese Journal of Rock Mechanics and Engineering, vol. 38, no. 5, pp. 1005-1017, 2019. 